\title{
A Current Overview of Diagnosis and Treatment in Retinopathy of Prematurity
}

\author{
Irfan Perente, ${ }^{1}$ Tulin Aras Ogreden ${ }^{2}$ \\ ${ }^{1}$ University of Health Sciences Beyoglu Eye Training and Research Hospital, Istanbul, Turkey \\ 2Suleymaniye Women Health Training and Research Hospital, Istanbul, Turkey
}

\begin{abstract}
Retinopathy of prematurity (ROP) is the interruption of the physiological development of retinal vascularization due to preterm delivery and is a proliferative vitreoretinopathy characterized by an evolving pathological process. Many innovations have emerged in the naming, screening, follow-up, and treatment of the disease in the 70 years since then first defined by Terry. This review is an examination of this difficult and dynamic area of modern-day ophthalmology practice in the light of current information.
\end{abstract}

Keywords: Plus disease, prematurity, threshold disease.

\section{Follow-up Protocols and Current Approach to Classification}

Retinopathy of prematurity (ROP) was first defined by Terry in 1942 (retrolental fibroplasia) (I). The disease is one of the most important causes of blindness in childhood, in both developed and emerging countries (2). Current data indicate that while blindness rate due to ROP varies from country to country, ROP developed in an estimated 184,700 preterm infants around the world in 2010 . Some 20,000 infants experienced severe vision loss or blindness as result of ROP (3). Birth week and low birth weight are the most important risk factors among many that have been defined (4). Screening protocols developed over the years have made great progress in early diagnosis. The American Academy of Pediatrics, the American Academy of Ophthalmology, the American Association for Pediatric Ophthalmology and Strabismus, and the American Association of Certified Orthoptists began to publish guidelines about first examination week, screening, and follow-up examinations in 1995. Revisions of 2000 and 2006 were updated in 2013, and it now includes statement that all infants born at $30^{\text {th }}$ gestational week or earlier or with birth weight of $1500 \mathrm{~g}$ or less should be screened (5). However, screening is also appropriate for infants with greater weight or other gestational age at birth who are considered at risk by pediatrician. Many countries have used international information as a base to create follow-up protocols in the light of national data. Canadian guideline also calls for screening infants with gestational age of 30 weeks or less, while guidelines of UK, Germany and Brazil recommend screening infants with gestational age of 32 weeks or less. Birth weight of $1500 \mathrm{~g}$ is independent criterion common to all countries; infants under $1500 \mathrm{~g}$ should be screened regardless of birth week.

Using national studies, Turkish premature retinopathy guide prepared in 2016 by the Turkish Neonatology Association and the Turkish Ophthalmology Association approved screening of all infants born before 32 weeks. Initial examination was determined to be at 3 Ist week for those born at 27 weeks or less, and postnatal fourth week for those born after $27^{\text {th }}$ week (6). International Classification of Retinopathy of Prematurity, first published in 1984, expanded in 1987, and revised in 2005, is used to describe the disease (7-9). 
The international classification system is based on 3 parameters: location of disease (zone), grade of vascular proliferation (stage), and degree of involvement (clock hours).

For classification of the zone, the retina is divided into 3 concentric circles with the optic nerve as the center. The radius of the circle defining zone I extends from the center of the optic disc to twice the distance from the center of the optic disc to the center of the macula. Zone II extends from border of zone I nasally to ora serrata and temporally to anatomical equator. Zone III is remaining crescent between zone II and temporal ora serrata.

Ophthalmoscopic findings at the junction between the vascularized and avascular retina define 5 stages of the disease. Stage $I$ is a faint demarcation line within the retinal plane. In stage 2 , there is a ridge with height, width, and volume gain on demarcation line. Stage 3 includes extraretinal fibrovascular proliferation formed by growth of fibrovascular tissue extending into the vitreous. There is subtotal retinal detachment (involving the macula or not) in stage 4 , and stage 5 is characterized by total retinal detachment.

Degree of spread of the disease is expressed with 12 clock-hour sectors of $30^{\circ}$. Tortuosity increase to at least 2 sectors in the posterior pole arteries and presence of dilatation in the veins is described as plus disease. Plus disease can be seen at any stage. Vitreous hemorrhage and blurring, vascular engorgement of the iris, and decrease in pupil reactions often accompany plus disease. Plus is an important criterion for defining threshold disease. Pre-plus disease is described as vascular abnormalities of the posterior pole that are insufficient for diagnosis of plus disease, but which demonstrate more arterial tortuosity and more venous dilatation than normal. Presence of pre-plus disease can be recorded using staging system as with plus disease, and may be useful in cases where more frequent follow-up is required.

\section{Current Approach in ROP Treatment}

Initially, cryotherapy was used to prevent development of sequelae. The efficiency, reliability, and long-term results of transscleral cryotherapy were investigated in the Cryotherapy for Retinopathy of Prematurity (CRYO-ROP) study (I0). Research revealed that cryoablation was successful, effective, and reliable method of stopping ROP progression in $75 \%$ of eyes. However, study also emphasized high disability values and unintended structural consequences observed in the long term. Broad spectrum of optotype acuities developed after successful treatment, with $75 \%$ demonstrating acuities worse than 20/40 at 10 and 15 years of age. In 1967, laser photocoagulation was used by Nagata et al. to treat ROP and became an increasingly popular approach for treatment of threshold disease. In the CRYO-ROP study published in 1988, threshold disease was defined as stage 3 disease or presence of plus through 5 sequential clock hours or 8 non-sequential clock hours in zone I or zone II. It is recommended that infants with threshold disease should be treated within 72 hours. Current indications for laser therapy in premature retinopathy are based on reports of the Early Treatment of Retinopathy of Prematurity (ETROP) study (II). Results of the ETROP study, published in 2003, defined 2 groups of pre-threshold disease.

High-risk pre-threshold disease was defined as any of the following: (I) zone I ROP, any stage, with plus disease; (2) zone I ROP, stage 3, without plus disease; or (3) zone II, stage 2 or 3 , with plus disease. Low-risk pre-threshold disease was defined as: (I) stage I or 2, not accompanied by plus disease in zone I; or (2) stage 3, without plus disease in zone II.

ETROP study demonstrated that early treatment provided significant reductions in adverse outcomes in high-risk, pre-threshold disease. It was determined that negative structural outcome ratio decreased from $15.6 \%$ to $9.1 \%$ when compared with conventional timing of laser therapy in highrisk pre-threshold disease, and follow-up was recommended for low-risk pre-threshold disease.

Although degree of disease regression after laser treatment may vary, it is relatively rapid. In study conducted by Coats et al., complete regression was observed at 2 weeks in half of the eyes treated with diode laser, with additional 3 weeks or more of treatment required in the remaining eyes. (I2). In general, response to treatment was observed within 6 or 12 weeks.

Laser photocoagulation is still accepted as classic treatment for ROP (13-16). However, it cannot be said that this method is smooth and satisfactory in every way. Large part of the retina is ablated by the laser and the veins are prevented from reaching the periphery. Insufficiently dilated pupils, lens opacity, or vitreous haze can make performing the treatment difficult.

Growth of vessels toward periphery of the retina can be induced with intravitreal anti- vascular endothelial growth factor (VEGF) application, a newer approach to ROP therapy that can achieve permanent maturation of retinal periphery. It is a salvage treatment for patients with small pupils and media opacity. In some series, it has been reported that anti-VEGF therapy can be performed as supportive treatment when fundus images cannot be obtained or laser treatment cannot be performed (17-19).

Aggressive posterior ROP (AP-ROP), when angiogenesis is interrupted at very early stages, can quickly progress to retinal detachment without pause in conventional, earlier stages of ROP, and often requires urgent treatment upon initial examination (9). Laser treatment is problematic in APROP patients when the macula is involved and there is an absence of classical zone and stage arrangement in retinal veins. Increasingly, studies have raised questions about whether in- 
travitreal injections will only be adjuvant treatment method, suggesting that anti-VEGF alone may be sufficient.

Some studies of intravitreal aflibercept injection in high-risk type I pre-threshold patients presented promising results using anti-VEGF agent for ROP treatment (20). Currently, bevacizumab and ranibizumab are primary ROP intravitreal applications. The Bevacizumab Eliminates the Angiogenic Threat of Retinopathy of Prematurity (BEAT-ROP) study was important clinical trial with large number of cases. This study was a prospective, randomized, controlled, multicenter trial that compared intravitreal bevacizumab monotherapy with conventional laser therapy in cases of stage 3+ ROP with zone I or II posterior disease. BEAT-ROP study demonstrated significantly higher rate of recurrence in zone I disease with conventional laser therapy compared with intravitreal bevacizumab monotherapy (42\% [ 14 of 33 infants] vs $6 \%$ [2 of 31 infants]; $p=0.003$ ). However, rate of recurrence in zone II posterior disease did not differ significantly between 2 groups ( $12 \%$ [5 of 40 infants] vs $5 \%$ [ 2 of 39 infants]; $p=0.27)$. The authors also observed difference in timeline

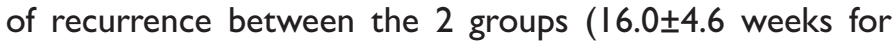
intravitreal bevacizumab vs $6.2 \pm 5.7$ weeks for conventional laser therapy). Macular traction was seen more frequently in cases treated with laser treatment (in 16 of 66 eyes in zone I cases, and in 6 of 80 eyes in zone II cases). While vitrectomy was performed in 13 of 66 eyes in laser treatment group and zone I cases, vitrectomy was performed in 2 of 78 eyes with zone II ROP cases in bevacizumab group.

Seven infants died during the follow-up period of that study: 5 in bevacizumab group and 2 in laser group. While it must be noted that the size of BEAT-ROP study (I50 infants) was not large enough to assess safety, results suggested superiority of intravitreal bevacizumab over conventional laser for treatment-requiring ROP in zone I (zone I, stage 3+ disease) (2I).

The Pan-VEGF Blockade for the Treatment of Retinopathy of Prematurity (BLOCK-ROP) study was designed to assess the safety and tolerability of bevacizumab in infants with APROP who had failed conventional laser therapy. Phase 2 of this study was to compare effect of bevacizumab at different doses with laser treatment. Goal was to investigate the risk of myopia and amblyopia, as well as the effect of various doses of bevacizumab and functional outcomes. Study included 3 groups of infants with type I threshold disease. Method outlined was $0.75 \mathrm{mg}$ or. $625 \mathrm{mg}$ intravitreal bevacizumab treatment in I eye and laser treatment on the other eye in the first group and second groups, respectively. Laser therapy was to be performed on both eyes in the third group (22). Unfortunately, due to difficult enrollment criteria, neither phase published results.

Nazari et al. reported that intravitreal injection of bevacizumab was effective for treatment of severe ROP associated with vitreous or retinal hemorrhage, and that no further injections or laser treatment were required (23). Another study found combination of intravitreal pegaptanib or bevacizumab injection and laser photocoagulation to be safe, well tolerated and effective therapy in patients with stage $3+$ ROP in zone I and posterior zone II (24). Furthermore, a review determined that compared with conventional laser or cryotherapy, intravitreal anti-VEGF injection showed significant benefit in terms of better final anatomic outcome, induction of prompt regression, rapid development of peripheral retinal vascularization, and decrease of recurrence rate of neovascularization. Results confirmed effectiveness of anti-VEGF treatment; however, it was noted that further study is still required (25).

It is hypothesized that intravitreal bevacizumab injection therapy may not be only be adjunctive therapy for stage 3 ROP, but may be regarded as treatment alternative with potency of replacing other treatments. At present, however, medical limitations and restrictions on the use of bevacizumab remain due to absence of long-term evidence-based effect and side-effect results, and use of bevacizumab is still "off-label" (26). VEGF is powerful neurotrophic and neuroprotective effective growth factor; it is not clear how retinal functions and neuronal development period are affected by suppression of VEGF (27). In addition, VEGF has role in development of retinal pigment epithelium (RPE) and choroidal vessels. Suppression of VEGF in rat model caused choroidal capillary atrophy and dysfunction in RPE (28). Complications such as endophthalmitis and traumatic injury of lens secondary to intraocular injection should not be overlooked, and furthermore, it should be considered that retinal detachment may be triggered by contraction in fibrous membranes (29). In some reports, post-menstrual gestational age follow-up periods extended up to $89.155 \pm 4.277$ weeks after anti-VEGF therapy (30). Therefore, it should be remembered that the length of time required for retinal vascular maturation after anti-VEGF treatment may result in frequent follow-ups for long period of time.

Current guidelines published in the USA in early 2013 include statement that intravitreal anti-VEGF therapy may be performed for zone I disease with detailed informed written consent from parents (5).

Bevacizumab treatment may also be performed after obtaining special permission for each patient with the Ministry of Health out of indication drug use form in Turkey. RAINBOW study (3I) is an international, multi-centered, randomized phase 3 study initiated in 2016 that compares ranibizumab with laser ablation treatment, examining efficiency, dose, and reliability. Turkey is a participant in the study.

There is still a need for more evidence on this issue; treatment for these patients is still an important problem that needs to be resolved. 


\section{Innovations and Current Approach in Imaging Technology}

Ability to record medical examination, overcome transport problems of patients, and economical use of time make telemedicine more and more important. RetCam (Clarity Medical Systems, Inc., Pleasanton, CA, USA) is wide-angle, digital, pediatric imaging system that provides fast imaging of the retina periphery with minimal stress to the patient (32). A more compact version is the RetCam Shuttle. This lighter, more maneuverable and more portable unit is suitable for telemedicine. Trained technical staff can examine ROP patients with mobile device and get advice about diagnosis and treatment from third-line reference centers. Low-cost scanning programs that include large geographic areas can be created using remote capability. This technique can easily be used by nurses and technicians, and is less stressful for the patient than indirect ophthalmoscopy, which requires more experience to perform and scleral depression. RetCam can also be used to reduce variability in approach of the observers. A very useful feature of RetCam is capacity to perform fundus fluorescein angiography to evaluate vascular structure. Different imaging lenses $\left(130^{\circ}, 120^{\circ}, 80^{\circ}, 30^{\circ}\right.$, and portrait) are available to adjust view for circumstances. In terms of efficacy, RetCam has been compared with gold standard of ROP diagnosis, indirect ophthalmoscopy, and has been praised for its high sensitivity and specificity (33).

Determining the extent of plus disease is typically very difficult, and may lead to differences in observations. One new diagnostic method uses computer software called ROPtool (developed at the University of North Carolina, Chapel Hill, and Duke University, and licensed by FocusROP), which measures the tortuosity of blood vessels in the retina and evaluates the density of tortuosity for evaluation of plus disease (34).

Other new devices include ICON (Phoenix Clinical, Inc., Pleasanton, CA, USA) pediatric retinal camera and the PanoCam (Visunex Medical Systems, Inc., Fremont, CA, USA) imaging system, which offer higher image quality, area, and contrast with simultaneous optical coherence tomography imaging capability.

Another useful development is retinal imaging and camera systems designed for smartphones. A common feature of many different devices designed for different models is lenticula placed between smartphone camera and the patient's eyes that take fundus images. This method is easy-toaccess, practical, and allows images to be shared easily ( 35 , 36). More knowledge about this increasingly popular application is needed to determine effectiveness and reliability in diagnosing and follow-up of ROP disease.

\section{New Treatment Prospects? Systemic Treatments?}

Conservative approaches, such as prevention, rational oxygen therapy, and reducing progression of ROP are still of concern while developments and studies on screening, diagnosis, and treatment methods are ongoing. It must be accepted that ROP is a multi-system disease, rather than just an ophthalmological problem. Systemic treatment should be planned with consideration given not only to underdevelopment of retina, but also the lungs, gastrointestinal system, liver, and immune system. Insulin-like growth factor I (IGF-I) is perhaps the most investigated mediator in this regard.

Insulin-Like Growth Factor I (IGF-I) in the Prevention of Complications of Preterm Birth study was an analysis of systemic IGF-I level in infants who developed ROP. Intravenous IGF-I supplementation was provided by injection to preterm infants with IGF-I level below physiological normal for gestational week until 3 Ist week of gestation before proliferative findings of ROP development had occurred. Study aimed to suppress proliferative phase by providing physiological vascularization by raising level of IGF-I to physiological level $(37,38)$.

Omega 3-fatty acids have also been investigated. In a study conducted by Connor et al. (39), it was observed that postnatal omega 3-fatty acid supplementation in oxygen-induced retinopathy model in mice suppressed preretinal proliferation by at least $40 \%$ and accelerated vascular arrangement in the avascular area of retina.

In another study, proliferation-suppressing potency of omega 3-fatty acids was compared with anti-VEGF treatment, and omega 3 -fatty acids were reported to be independent of VEGF in retinal neovascularization and retinal angiogenetic activity (40).

Inhibitory effect on development of ROP disease associated with oxidative stress of antioxidant vitamin $E$ has long been emphasized (4I). In meta-analysis of controlled clinical studies, 536 patients were evaluated, and it was reported that ROP at any stage was detected in $39.8 \%$ of patients who were given vitamin $E$ and in $43.5 \%$ of the controls, and stage 3 ROP developed in $2.4 \%$ of patients in vitamin E group, and $5.3 \%$ in control group (42).

Treatment of ROP has gradually reached cellular and molecular dimension. Gene therapies including VEGF; matrix metalloproteinase- 2 inhibitors, which can affect angiogenesis by digesting basal membrane with components extracellular matrix; and gold nanoparticles used to reduce oxidative stress are promising approaches in this regard (43).

Small interference RNA products, such as sirna-027 (Sirna Therapeutics, Inc. San Francisco, CA, USA), and ruboxistaurin mesylate (Arxxant; Eli Lilly and Co., Indianapolis, IN, USA), which inhibit tyrosine kinase and block VEGF and VEGFR synthesis are newly generated anti-VEGF agents still under investigation in age-related macular degeneration and diabetic macular edema treatment and could possibly be used in treatment of ROP (44). 
Although medical advances may open new horizons to ophthalmologists in diagnosis and treatment of ROP, it appears that it will continue to be a challenging area of daily practice. Establishment of co-operative teams made up of members of different specialties and full implementation of screening protocols, establishment of fully equipped reference centers, increased use of telemedicine, and patient-centered treatment approaches will continue to be the best hope for many newborns who start unlucky in life.

\section{Disclosures}

Peer-review: Externally peer-reviewed.

Conflict of Interest: None declared.

Authorship Contributions: Preparation and review - IP, TAO.

\section{References}

I. Terry TL. Extreme prematurity and fibroblastic overgrowth of persistent vascular sheath behind each crystalline lens. Am J Ophthalmol 1942;25:203-4. [CrossRef]

2. Miller MM, Revenis ME, Lai MM, Meleth AD, Jeffress ES, Carrera $A$, et al. Risk and clinical course of retinopathy of prematurity in 78 infants of gestational age 22-25 weeks. J AAPOS 20|4; |8:266-70. [CrossRef]

3. Blencowe H, Lawn JE, Vazquez T, Fielder A, Gilbert C. Preterm-associated visual impairment and estimates of retinopathy of prematurity at regional and global levels for 2010. Pediatr Res 2013;74 Suppl I:35-49. [CrossRef]

4. Günay M, Topçuoğlu S, Çelik G, Gürsoy T. Prematüre retinopatisi: Sıklık azalıyor mu? Zeynep Kamil Tip Bult 20।3;44:2।4-20.

5. Fierson WM; American Academy of Pediatrics Section on Ophthalmology; American Academy of Ophthalmology; American Association for Pediatric Ophthalmology and Strabismus; American Association of Certified Orthoptists. Pediatrics. Screening examination of premature infants for retinopathy of prematurity. Pediatrics 2013;131:189-95. [CrossRef]

6. Section on Ophthalmology American Academy of Pediatrics; American Academy of Ophthalmology; American Association for Pediatric Ophthalmology and Strabismus. Screening examination of premature infants for retinopathy of prematurity. Pediatrics 2006; I 17:572-6. [CrossRef]

7. An international classification of retinopathy of prematurity. II. The classification of retinal detachment. The International Committee for the Classification of the Late Stages of Retinopathy of Prematurity. Arch Ophthalmol 1987;105:906-12.

8. An international classification of retinopathy of prematurity. The Committee for the Classification of Retinopathy of Prematurity. Arch Ophthalmol 1984; 102:I I30-4. [CrossRef]

9. International Committee for the Classification of Retinopathy of Prematurity. Arch The International Classification of Retinopathy of Prematurity revisited. Ophthalmol 2005; I23:99I-9.

10. Multicenter trial of cryotherapy for retinopathy of prematurity.
Preliminary results. Cryotherapy for Retinopathy of Prematurity Cooperative Group. Arch Ophthalmol 1988;106:47I-9.

I I. Early Treatment For Retinopathy Of Prematurity Cooperative Group. Revised indications for the treatment of retinopathy of prematurity: results of the early treatment for retinopathy of prematurity randomized trial. Arch Ophthalmol 2003; | 21:1684-94. [CrossRef]

12. Coats DK, Miller AM, Brady McCreery KM, Holz ER, Paysse EA. Involution of thresh-old retinopathy of prematurity after diode laser photocoagulation. Ophthalmology 2004; I I I:I8948. [CrossRef]

13. Jordan CO. Retinopathy of prematurity. Pediatr Clin North Am 20|4;61:567-77. [CrossRef]

14. Vartanian RJ, Besirli CG, Barks JD, Andrews CA, Musch DC. Trends in the Screening and Treatment of Retinopathy of Prematurity. Pediatrics 2017;139. pii: e20161978. [CrossRef]

15. Mutlu FM, Sarici SU. Treatment of retinopathy of prematurity: a review of conventional and promising new therapeutic options. Int J Ophthalmol 2013;6:228-36.

16. Gonzalez VH, Giuliari GP, Banda RM, Guel DA, Wingard M. Confluent laser photocoagulation for the treatment of retinopathy of prematurity. J Pediatr Ophthalmol Strabismus 2010;47:8I-5. [CrossRef]

17. McLoone E, O'Keefe M, McLoone S, Lanigan B. Long term functional and structural outcomes of laser therapy for retinopathy of prematurity. Br J Ophthalmol 2006;90:754-9. [CrossRef]

18. Mintz-Hittner HA, Best LM. Antivascular endothelial growth factor for retinopathy of prematurity. Curr Opin Pediatr 2009;2 I: I82-7. [CrossRef]

19. Quiroz-Mercado H, Martinez-Castellanos MA, Hernandez-Rojas ML, Salazar-Teran N, Chan RV. Antiangiogenic therapy with intravitreal bevacizumab for retinopathy of prematurity. Retina 2008;28:S19-25. [CrossRef]

20. Salman AG, Said AM. Structural, visual and refractive outcomes of intravitreal aflibercept injection in high-risk prethreshold type I retinopathy of prematurity. Ophthalmic Res 2015;53:I520. [CrossRef]

2I. Geloneck MM, Chuang AZ, Clark WL, Hunt MG, Norman AA, Packwood EA, et al; BEAT-ROP Cooperative Group. Refractive outcomes following bevacizumab monotherapy compared with conventional laser treatment: a randomized clinical trial. JAMA Ophthalmol 2014; 132:1327-33. [CrossRef]

22. Pan-VEGF Blockade for the Treatment of Retinopathy of Prematurity (BLOCK-ROP). Available at: https://clinicaltrials.gov/ ct2/show/NCT00702819. Accessed May 30, 2017.

23. Nazari H, Modarres M, Parvaresh MM, Ghasemi Falavarjani K. Intravitreal bevacizumab in combination with laser therapy for the treatment of severe retinopathy of prematurity (ROP) associated with vitreous or retinal hemorrhage. Graefes Arch Clin Exp Ophthalmol 2010;248:17/3-8. [CrossRef]

24. Autrata R, Senková K, Holousová M, Krejcírová I, Dolezel Z, 
Borek I. Effects of intravitreal pegaptanib or bevacizumab and laser in treatment of threshold retinopathy of prematurity in zone I and posterior zone II-four years results. Cesk Slov Oftalmol 2012;68:29-36.

25. Chawla D, Darlow BA. Anti-Vascular Endothelial Growth Factor Preparations in the Treatment of Retinopathy of Prematurity: Balancing Risks and Benefits. Indian Pediatr 2016;53 Suppl 2:SI29-SI36.

26. Recchia FM, Capone A. Update on anti-VEGF monotherapy for ROP. Rev Ophthalmol 20I I. Available at: https://www.reviewofophthalmology.com/article/update-on-anti-vegf-monotherapyfor-rop. Accessed: 07.10.2017.

27. Nishijima K, Ng YS, Zhong L, Bradley J, Schubert W, Jo N, et al. Vascular endothelial growth factor-A is a survival factor for retinal neurons and a critical neuroprotectant during the adaptive response to ischemic injury. Am J Pathol 2007; |71:53-67.

28. Marneros AG, Fan J, Yokoyama Y, Gerber HP, Ferrara N, Crouch RK, et al. Vascular endothelial growth factor expression in the retinal pigment epithelium is essential for choriocapillaris development and visual function. Am J Pathol 2005; I67:|45 I-9.

29. Zepeda-Romero LC, Liera-Garcia JA, Gutiérrez-Padilla JA, Valtierra-Santiago Cl, Avila-Gómez CD. Paradoxical vascular-fibrotic reaction after intravitreal bevacizumab for retinopathy of prematurity. Eye (Lond) 2010;24:93I-3. [CrossRef]

30. Yetik H, Gunay M, Sirop S, Salihoglu Z. Intravitreal bevacizumab monotherapy for type-I prethreshold, threshold, and aggressive posterior retinopathy of prematurity - 27 month follow-up results from Turkey. Graefes Arch Clin Exp Ophthalmol 20I5;253:1677-83. [CrossRef]

31. RAINBOW Study: Ranibizumab Compared With Laser Therapy for the Treatment of Infants Born Prematurely With Retinopathy of Prematurity. Available at: https:/clinicaltrials.gov/ ct2/show/NCT0237597I. Accessed May 30, 2017.

32. Trese MT, Azad R. Prematüre retinopatisi. Istanbul: Hiper Tıp; 20I3. p. 93-4.

33. Tejada-Palacios P, Zarratea L, Moral M, de la Cruz-Bértolo J. Comparative study of RetCamRetCam II vs. binocular ophthalmoscopy in a screening program for retinopathy of prematurity. Arch Soc Esp Oftalmol 2015;90:373-8. [CrossRef]
34. Wallace DK, Freedman SF, Zhao Z. Evolution of plus disease in retinopathy of prematurity: quantification by ROPtool. Trans Am Ophthalmol Soc 2009; 107:47-52.

35. Sharma A, Subramaniam SD, Ramachandran KI, Lakshmikanthan C, Krishna S, Sundaramoorthy SK. Smartphone-based fundus camera device (MII Ret Cam) and technique with ability to image peripheral retina. Eur J Ophthalmol 2016;26: I42-4.

36. Russo A, Morescalchi F, Costagliola C, Delcassi L, Semeraro F. A Novel Device to Ex-ploit the Smartphone Camera for Fundus Photography. J Ophthalmol 20I5;2015:823 I39. [CrossRef]

37. Hellström A, Engström $E$, Hård $A L$, Albertsson-Wikland $K$, Carlsson B, Niklasson A, et al. Postnatal serum insulin-like growth factor I deficiency is associated with retinopathy of prematurity and other complications of premature birth. Pediatrics 2003; I 12:1016-20. [CrossRef]

38. Löfqvist C, Engström E, Sigurdsson J, Hård AL, Niklasson A, Ewald $U$, et al. Postnatal head growth deficit among premature infants parallels retinopathy of prematurity and insulin-like growth factor-I deficit. Pediatrics 2006; I 17:1930-8. [CrossRef]

39. Connor KM, SanGiovanni JP, Lofqvist C, Aderman CM, Chen J, Higuchi $A$, et al. Increased dietary intake of omega-3-polyunsaturated fatty acids reduces pathological retinal an-giogenesis. Nat Med 2007; | 3:868-73. [CrossRef]

40. Aiello LP, Pierce EA, Foley ED, Takagi H, Chen H, Riddle L, et al. Suppression of retinal neovascularization in vivo by inhibition of vascular endothelial growth factor (VEGF) using soluble VEGF-receptor chimeric proteins. Proc Natl Acad Sci U S A | 995;92: |0457-6|. [CrossRef]

4I. Thibeault DW. The precarious antioxidant defenses of the preterm infant. Am J Perinatol 2000; 17:I67-8I. [CrossRef]

42. Raju TN, Langenberg P, Bhutani V, Quinn GE. Vitamin E prophylaxis to reduce retinopathy of prematurity: a reappraisal of published trials. J Pediatr 1997; | 3 1:844-50. [CrossRef]

43. Monika M, Katarzyna KK, Leszek K. Present-day conservative treatment retinopathy of prematurity. Klin Oczna 20 I 3; I I 5:658.

44. Çakmak H, Karabulut M, Kocatürk T. Anti-VEGF agents and the uses of these agents in eye diseases. Selcuk Tip Derg 20|4;30:93-6. 